\title{
THE EFFECT OF MATING ON CALLTNG IN CYPHODERRIS STREPITANS
}

Scott K. Sakaluk

Glenn K. Morris

Department of Zoology and Erindale College

University of Toronto

Ontario

and

W. Andrew Snedden

Department of Biological Sciences

Brock University

St. Catharines

Ontario

\section{Objectives}

Cyphoderris strepitans Morris \& Gwynne (Haglidae) is a cricket-like insect occurring in sagebrush habitats in Grand Teton National Park. The males of this primitive orthopteran produce sounds by rubbing together stridulatory structures located on their forewings (Morris \& Gwynne 1978). They emerge from the litter beneath the sage shortly after sunset, climb into the bushes and begin to call; matings take place in sage bushes or on the ground some time thereafter (Dodson et al. 1983).

Males also practice courtship feeding of females, providing them with two types of nuptial food gifts. First, females feed on the male's fleshy metathoracic wings and the resultant flow of blood during copulation (Morris 1979). Second, the spermatophore transferred by the male includes a large gelatinous non-sperm portion, the spermatophylax, which apparently is eaten by the female after mating (Dodson et al. 1983).

In other ensiferan Orthoptera, acoustic signalling by males functions to attract sexually receptive females (reviews in Morris et al. 1975) and serves also as a threat to conspecific males, providing a space around callers free of signalling competitors (e.g. Morris 1971, Cade 1979). The function of calling in C. strepitans is unknown; attempts to demonstrate female phonotaxis in the laboratory have been unsuccessful (Morris 1985).

Previous study of a population during the peak of mating season activity showed that non-virgin male $\underline{C}$. strepitans subseguently mate significantly less often than virgin males (Morris 1982). At least two hypotheses can account for the reduced mating success of non-virgin male C. strepitans. First, non-virgin males may not call as frequently as virgins. Stridulation is an energetically costly activity and non-virgin males, having lost substantial available energy through 
wing feeding and the transfer of a large spermatophore, may lack the resources necessary to call at a level equivalent to that prior to their initial mating. Reduced calling should result in the attraction of fewer females and/or a greater risk of intrusion from competing males and consequently a lowered mating success.

Alternatively or in addition, females may actively discriminate against non-virgin males (see Parker's (1982, 1983) distinction between passive and active female choice). Non-virgin males, having lost a large fraction of their resources in previous matings, may have less feeding material to offer females in subsequent matings. This is particularly true of the metathoracic wing material which, once eaten cannot be regenerated. Assuming that resources provided to females by males are important to female reproduction, females may be selected to discriminate against males who would provide them with inadequate nuptial gifts. This hypothesis does not require a difference in calling behavior of virgin and non-virgin males, but merely that females be able to distinguish between the two male types.

Our objective in 1986 was to test a prediction of the first of these hypotheses, specifically to determine whether mating is attended by a reduction in subsequent singing activity by males. Specimens collected from a natural population were housed in the laboratory and the calling behaviour of virgin and non-virgin males compared, examining differences in durations and other temporal patterns of acoustic signalling in these two groups. We also assessed the relationship between male body weight and calling time within individuals of identical mating status.

\section{Methods}

The study was conducted from May 18 to June 8 in Grand Teton National Park. Males were collected from two sites within the park, one at Deadman's Bar and the other at Pacific Creek. Captured males were classified as non-virgin if their hind wings exhibited the wounds characteristic of mated males and as virgin if their wings were free of such wounds. It was also possible to distinguish males that had mated on the night of capture (fresh wounds) from males that had mated previous to the night of capture (old wounds). This additional classification was enabled because the wounds of newly mated males normally appear wet (i.e. show signs of bleeding) and exhibit little sign of discoloration, whereas the wounds of males mated on previous nights are dry and show considerable darkening.

We sampled the singing activity of individual male C. strepitans in all three mating categories, virgin, ald wound non-virgins, and freshly wounded non-virgins. However, our electronic sound relay apparatus could accomodate only 12 males at a time. To ensure an adequate sample size, it was necessary to monitor several consecutive series of 12-male groups. For each 12-male group, we attempted to monitor an equal number of males from each category to control for changes in calling activity over the season. Although equal representation usually was not achieved, each group always included at least one male from each category. In addition, the total number of males monitored 
from each category was almost identical in the first half of the experiment (16 virgins, 15 ald wounds, 15 fresh wounds) and in the second (15 virgins, 16 ald wounds, 16 fresh wounds). Thus there was no systematic seasonal bias in our acoustical assays across experimental categories.

Males were captured at night during the first 3-4 hr following sunset. The following morning, they were weighed to the nearest $0.1 \mathrm{mg}$ with a Roller-Smith torsion balance, placed in a sound monitoring apparatus (see below), and their calling activity monitored over each of the next two nights. On the second night of monitoring, a new cohort of 12 males was collected and used the next morning to replace previously monitored males.

The sound monitor system consisted of a specially designed microprocessor with inputs accomodating 12 electret miccophones (Realistic 33-1060); data were transferred electronically to a teletype (Leigh Instruments) which provided a permanent printed record. Calling activity was electronically assayed at 4-second intervals. Sound detected at a microphone during any of these instantaneous sampling periods was scored by the processor at $4 \mathrm{~s}$ of calling. These 4-second bouts of calling were cumulated and printed out at 15-min intervals throughout the night.

The microprocessor was programmed to respond maximally to sound frequencies in the range of $12-14 \mathrm{kHz}$ since the calling song of $\mathrm{C}$. strepitans has its dominant cancier frequency peak at $12.7 \mathrm{kHz}$ (Monris and Gwynne 1978). Thus the system was insensitive to most background sounds. We tested the system prior to the experiment using playback of a previously recorded calling song. The signal was broadcast through a speaker placed $10 \mathrm{~cm}$ from the microphone at a sound level of $90 \mathrm{~dB}$ (A weighting, re 20 microPa). This sound level is comparable to that produced by live males (Monis and Gwynne 1978). The initial test allowed us to determine if acoustic activity at one microphone could be detected at adjacent ones and to establish that each microphone functioned. The system also was tested at the end of the experiment at which time each microphone was found to show a consistent response to the playback of calling song.

Males were placed in small individual aluminum screen cages $(8 \mathrm{~cm} \mathrm{X} 15 \mathrm{~cm})$; mesh size was $0.2 \mathrm{~cm}$. Each cage was provisioned with a piece of apple and placed on a pad of $2.5 \mathrm{~cm}$ thick fibreglass insulation $(20.5 \mathrm{~cm} \mathrm{X} 15 \mathrm{~cm})$. This arrangement was subsequently enclosed in a larger cage, consisting of three walls (32 cm (height) X $23 \mathrm{~cm}$ (width) and a ceiling $(23 \mathrm{~cm} \times 23 \mathrm{~cm}$ ) made of hardware cloth; the fourth wall was of $0.3-\mathrm{cm}$ thick plexiglass; the cage had an open bottom. The larger cage served as a support for the microphone and a lining ( $35.5 \mathrm{~cm}$ height) of additional insulation which surrounded the small cage. A microphone was inserted through a hole in the roof of the larger cage and suspended approximately $5 \mathrm{~cm}$ directly above the smaller cage.

Large cages were arranged on a table in two rows of six; the rows were placed $25 \mathrm{~cm}$ apart and were separated by a wall of $2.5-\mathrm{cm}$ styrofoam, $35.5 \mathrm{~cm}$ in height. Individual cages were placed $10 \mathrm{~cm}$ apart and arranged so that the plexiglass wall of one cage faced a neighboring cage. These additional precautions were taken to prevent acoustical activity in one cage being 
detected at adjacent microphones.

The table on which the experiment was camied out was situated beneath a window in the laboratory. Experimental animals were exposed therefore to the ambient photoperiod, although the light intensity in the room was somewhat lower than outside. A baseboard heater prevented the temperature in the room from falling below 8.9 C. During the entire course of the experiment the temperature ranged between 8.9-18.3 C.

\section{Results}

Time spent calling

The average time spent calling by males of the three experimental groups is shown in Table 1. Calling times within groups were not normally distributed (D'Agostino's test, $p<0.05$ ), so the Druskal-Wallis nonparametric rank test was used to test for intergroup differences. There were no significant differences between groups in time spent calling on the first night of electronic monitoring $\left(\mathrm{chi}^{2}=3.94, \mathrm{p}>0.05\right)$, time spent calling on the second night (chi ${ }^{2}=4.26, \mathrm{p}>$ 0.05 ), or total calling over both nights $\left(\mathrm{chi}^{2}=3.95, \mathrm{p}>0.05\right)$. This same analysis was applied to groups excluding those males that did not call on at least one of the two nights (i.e. silent males). Differences between groups remained statistically non-significant for first-night $\left(\mathrm{chi}^{2}=4.57, p>0.05\right)$, second-night $\left(\mathrm{chi}^{2}=2.66, p>0.05\right)$ and total calling time $\left(\mathrm{chi}^{2}=2.66, p>0.05\right)$ and total calling time $\left(\mathrm{chi}^{2}=2.88, \mathrm{p}>0.05\right)$.

Differences between groups only became apparent when the amount of calling on the first night was compared to that occurring on the second night (Table 1). Calling times on the first and second nights did not differ for virgin males ( $W$ ilcosson paired-sample test, $W+=46.5, n=18, p>0.05$ ). However, for both the old-wound $(w+=12.5, n=20, p<0.001)$ and fresh-wound categories $(w+=$ $20.5, n=14, p<0.05)$, males called significantly less on the first night than on the second night.

We also determined the proportion of males in each group that called on both nights (Table 1). A contingency table analysis showed that the percentage of males that called on both nights differed significantly among experimental groups $\left(\mathrm{chi}^{2}=7.08, \mathrm{p}<0.05\right)$. A posteriori pairwise comparisons were made using the Tukey-type multiple comparison for proportions (Zar 1984). A significantly greater proportion of virgin males than freshly wounded males called on both nights ( $q=7.60, p<0.001$ ), as did a significantly greater proportion of ald-wound males $(q=5.38, p<0.001)$. The proportions of virgin and old-wound males calling on both nights did not, however, differ significantly $(\mathrm{Q}=2.22, \mathrm{p}>0.05)$.

Temporal pattern of calling

Data on the temporal occurrence of acoustic signalling behaviour are shown in Table 2. Generally, calling began at about $2100 \mathrm{~h}$ and ended at about $2400 \mathrm{hr}$. For any given night, the duration over which a male called was defined as the 


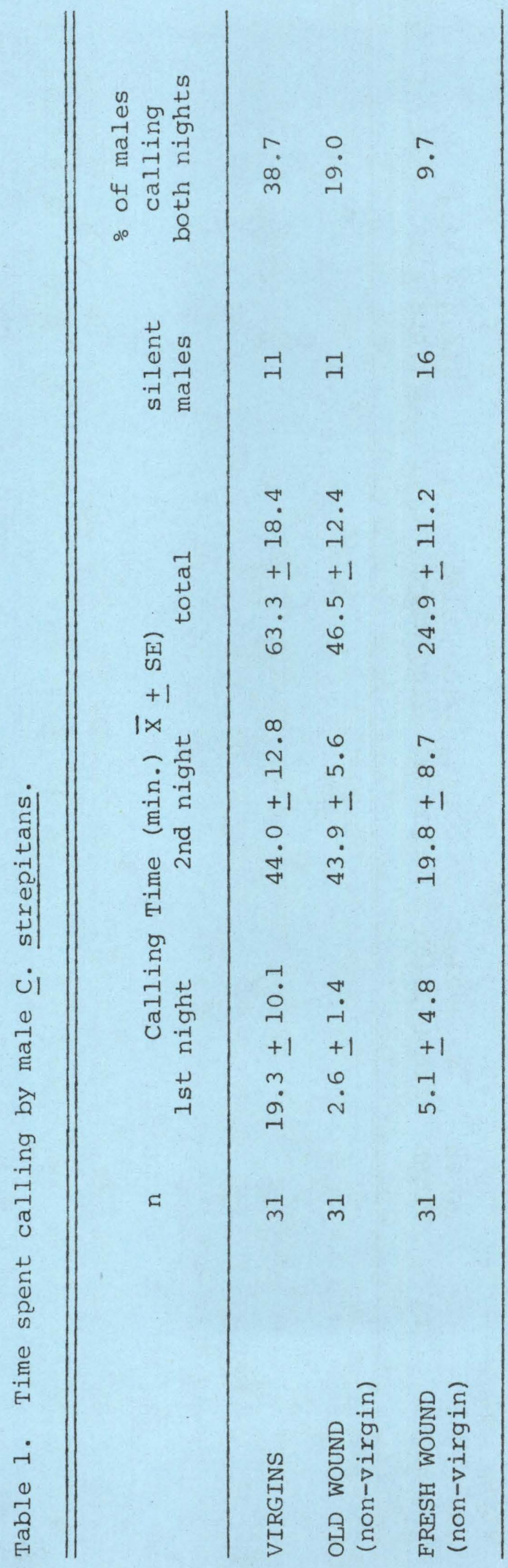




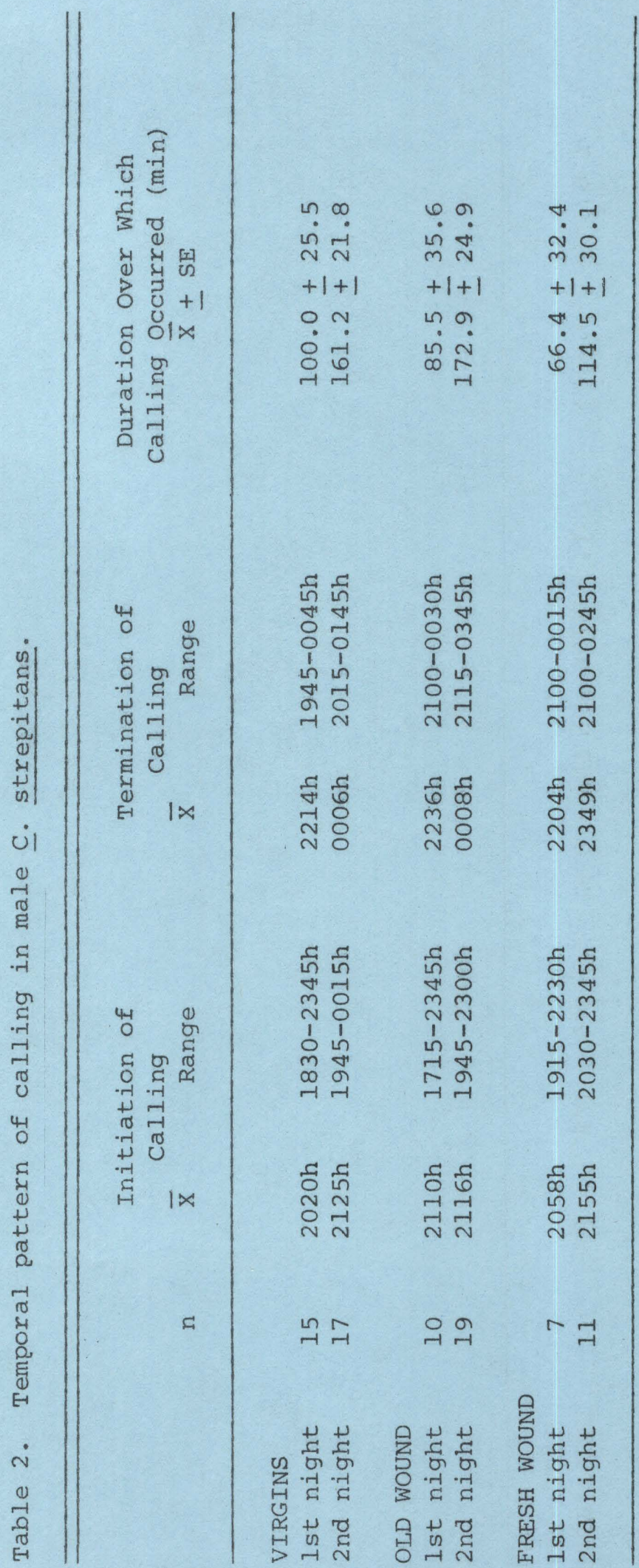


interval between the first and last occurrence of the male's acoustic signalling behavior. For each of the two nights that males were monitored, only males that called at least once, by definition, were included in the computations. There were no significant differences between groups in the mean duration over which males called on either the first (ANOVA; $F=0.27, p>0.05$ ) or second night of monitoring $(F=1.23, \mathrm{p}>0.05)$.

Clear differences between groups emerged when the duration over which males called on the first night was compared with that of the second night (Table 2). For virgin males, there was no significant difference in the mean duration over which calling occurred on the first night versus that of the second (paired $t$ test; $t=1.79, p>0.05)$. For old-wound males however, the duration over which calling occurred on the first night was significantly shorter than that of the second night $(t=-2.447, p<0.05)$. This difference in calling duration between nights was not due to an earlier initiation of calling activity by ald-wound males on the second night, versus that of the first ( $t=-0.30, p>0.05$ ). Rather, acoustic signalling ended significantly later on the second night $(t=-3.30$, $p<$ 0.025). In all but one of the nine cases in which an old-wound male called on both nights, the male ceased calling later the second night than the first. First and second-night calling durations could not be compared for the fresh-wound category due to an insufficient number of callers $(n=3)$.

\section{Male weight and calling time}

The mean weight of males for each experimental category is shown in Table 3. Although as expected, virgin males weighed the most and freshly wounded non-virgin males weighed the least, differences between groups were only marginally significant statistically $(F=2.96,0.05<p<0.1)$. We also examined the relationship between the initial weight of a male and the total time he spent calling over both nights: 1) within experimental categories and 2) for all males regardless of mating success. In no instance, was there a significant correlation between male weight and time spent calling (Spearman rank correlation, $p>0.05)$. Neither was the correlation significant when silent males were excluded from the analyses ( $p>0.05$ ).

\section{Discussion}

Our data show a significant though short-term reduction in signalling activity by male $\underline{C}$. strepitans as a consequence of mating. Whereas there was no difference in the time spent calling by virgins on the first and second nights following capture, both freshly wounded and old-wound non-virgins called significantly less on the first night than on the second. Furthermore, the proportion of males calling on both nights was significantly greater for the virgin and old-wound groups than for freshly wounded (i.e. recently mated) males. When the duration over which males called on the first night was compared with that of the second, virgin males showed no difference whereas old-wound males called over significantly shorter intervals on the first night relative to those of the second; the comparison could not be applied to the freshly wounded males because too few individuals of that group called on both nights. 


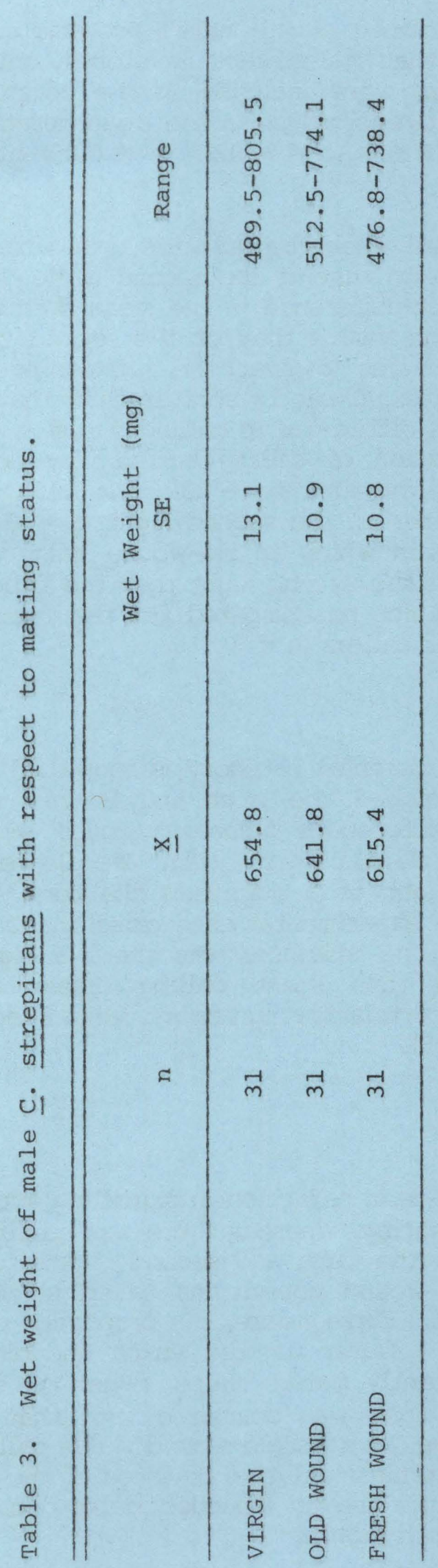


These results can be interpreted as follows: the cost of a large nutrient investment in females lowers the energy level in male $\mathrm{C}$. strepitans below the threshold required for the maintenance of a prolonged signalling period. After a refractory interval during which males feed and replenish their energy reserves, calling levels equivalent to those which occur prior to mating are regained. The trauma of capture could also explain the reduced calling of non-virgin males on the first night; but we reject this hypothesis because no capture effect was observed in virgin males for any calling parameter. Virgin males weighed more than the old-wound non-virgins which in turn, weighed more than the freshly wounded non-virgins; this ordering of groups matched that found for total calling time. Dodson et al. (1983) also found that virgin male $C$. strepitans weighed more than non-virgins, but as in our study, the differences were marginally short of statistical significance.

Even a brief period of non-calling (e.g. one night) must incur considerable costs, since in the population of $C$. strepitans which we studied, most matings occur within a period of several days (Dodson et al. 1983, Morris 1982). The length of the refractory period required by non-virgin males in this study must be considered a minimum estimate. In the field, non-virgin males may have to forage over considerable distances and for longer periods in order to obtain food resources sufficient to replace energy lost in mating. Under our experimental protocol, males were provisioned with a generous portion of apple; foraging costs undoubtedly were reduced, therefore, such that males could more quickly regain weight lost in mating. Supporting this suggestion, male C. strepitans similarly provisioned in past studies, exhibited substantial and rapid weight gains (Dodson et al. 1983).

\section{Conclusions}

In C. strepitans copulation and its attendant costs, contributes to a short-term reduction in subsequent acoustic signalling activity, which may partially explain the reduced remating success of non-virgin males of this species.

\section{Literature Cited}

Cade, W. 1979. The evolution of alternative male reproductive strategies in field crickets. In M.S. Blum and N.A. Blum eds. Sexual selection and reproductive competition in insects. Academic Press, New York.

Dodson, G. N., G. K. Morris and D. T. Gwynne. 1983. Mating behavior of the primitive orthopteran genus Cyphoderris (Haglidae). In D. T. Gwynne and G. K. Morris eds. Orthopteran mating systems. Westview, Boulder.

Morris, G. K. 1971. Aggression in male conocephaline grasshoppers (Tettigoniidae). Ani. Behav. 19:132-137.

Morris, G. K. 1979. Mating systems, paternal investment and aggressive behavior of acoustic Orthoptera. Fla Entomol. 62:9-17. 
Morris, G. K. 1982. Differential pairing and mating in the primitive insect Cyphoderris strepitans (Orthoptera:Haglidae). Univ. Wyoming - Nat. Pk. Serv. Res. Center 6th Ann. Rep.

Morris, G. K. 1985. Acoustic behavior in Cyphoderris strepitans. Univ. Wyoming - Nat. Pk. Serv. Res. Center 9th Ann. Rep.

Morris, G. K., G. E. Kerr, and D. T. Gwynne. 1975. Calling song function in the bog katydid, Metrioptera sphagnorum (F'. Walker) (Orthoptera, Tettigoniidae). z. Tierpsychol. 37:502-514.

Morris, G. K. and D. T. Gwynne. 1978. Geographical distribution and biological observations of Cyphoderris (Orthoptera:Haglidae) with a description of a new species. Psyche 85:147-167.

Parker, G. A. 1982. Phenotype-limited evolutionarily stable strategies. In B.R. Bertram et al. eds. Current problems in sociobiology. Cambridge Univ. Press, Cambridge.

Parker, G. A. 1983. Mate quality and mating decisions. In P. Bateson ed. Mate choice. Cambridge Univ. Press, Cambridge.

Zar, J. H. 1974. Biostatistical analysis. Prentice-Hall, New Jersey. 